\title{
TROCHLEA SULCUS AND LATERAL TROCHLEA INCLINATION ANGLES IN KENYANS: AN OSTEOMETRIC STUDY
}

\author{
Lakati Kevin Christopher *, Arisi Kerubo, Yegon Fred, Mwaniki Mark, Mutero Flora.
}

Department of Human Anatomy, Faculty of Health Sciences, Egerton University, Kenya.

\section{ABSTRACT}

Background: The trochlea sulcus and lateral trochlea inclination angles have important implications in the biomechanics of the patellofemoral joint. Abnormalities of these angles have been implicated in patella instability, anterior knee pain and patella complications after both total knee and patellofemoral arthroplasty.

Objective: To measure the trochlea sulcus and lateral trochlea inclination angles on dried unpaired Kenyan femora.

Methods: The angles were measured on end-on digital images of grossly normal femora using an open source image analysis software, Image ${ }^{\circledR}$. Measures of central tendency were calculated.

Results: Average trochlea sulcus and lateral trochlea inclination angles were 1390 and 210 respectively. There was no significant difference between the angles in the right and left femora. There was a negative correlation between the sulcus and lateral trochlea inclination angles. These angles are comparable to values in other populations.

Conclusion: Average sulcus angle in Kenyan femora is 1390 and the average lateral trochlea inclination angle 210, with no significant difference between right and left sides. These can be used as guide when analyzing diagnostic images of the knee for patella instability.

KEY WORDS: Trochlea Sulcus Angle, Lateral Trochlea Inclination, Patella Instability.

Corresponding Author: Lakati Kevin Christopher, Lecturer, Department of Human Anatomy, Faculty of Health Sciences, P.O. Box 536-20115. Egerton University, Kenya.

E-Mail:klakati@yahoo.com

Access this Article online

Quick Response code

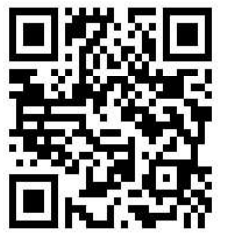

DOI: $10.16965 /$ ijar.2020.176

Journal Information

International Journal of Anatomy and Research

RG Journal ISSN (E) 2321-4287 | ISSN (P) 2321-8967

Impact: 0.21* https://www.ijmhr.org/ijar.htm

DOI-Prefix: https://dx.doi.org/10.16965/ijar

\section{Article Information}

Received: 16 Jun 2020

Peer Review: 18 Jun 2020

Revised: None
Accepted: 28 Jul 2020

Published (O): 10 Aug 2020

Published (P): 10 Aug 2020

\section{BACKGROUND}

The trochlea sulcus angle, located at the distal end of the femur, is formed at the femoral trochlea groove by the junction of two straight lines that extend from the highest points of both the medial and lateral condyles and intersect within the trochlea groove [1]. The angle has important implications in the biomechanics of the patellofemoral joint. Abnormalities of the sulcus angle and the femoral trochlea have been implicated in patella instability, extensor apparatus malalignment and anterior knee pain $[2,3]$. In some patients, these abnormalities of the angle and the patellofemoral joint complex may predispose to osteoarthritis of the joint [4]. The lateral trochlea inclination angle is the angle formed between a line tangential to the posterior aspect of the condyles and a line along the anterior aspect of the lateral trochlea facet [5]. A lateral trochlea inclination angle of less than $11^{0}$ indicates trochlea dysplasia and is associated with patella instability [5]. The trochlea sulcus and lateral inclination angles have important bearing in both total knee and patellofemoral arthroplasty. 
Patellofemoral complications are common after total knee and patellofemoral arthroplasty and are responsible for patient dissatisfaction and revisions. These complications range from maltracking, subluxation, dislocation, pain and loosening [6,7]. In patellofemoral arthroplasty, the morphology of the trochlea has an important bearing on component positioning. Malposition of the component leads to patella maltracking and subluxation [8]. Newer designs of total knee arthroplasty components have a more anatomic trochlear sulcus compared to earlier designs, in an attempt to minimize postoperative patellofemoral complications [9]. This study sought to determine the trochlea sulcus and lateral trochlea inclination angles of adult Kenyan femora and compare them with results of other published studies.

\section{MATERIALS AND METHODS}

Dry unpaired femora were obtained from the Department of Human Anatomy, Egerton University, Kenya. Only skeletally mature specimens were used. Specimens that looked grossly deformed, those with previous fractures or surgery and those with postmortem damage were excluded from the study.

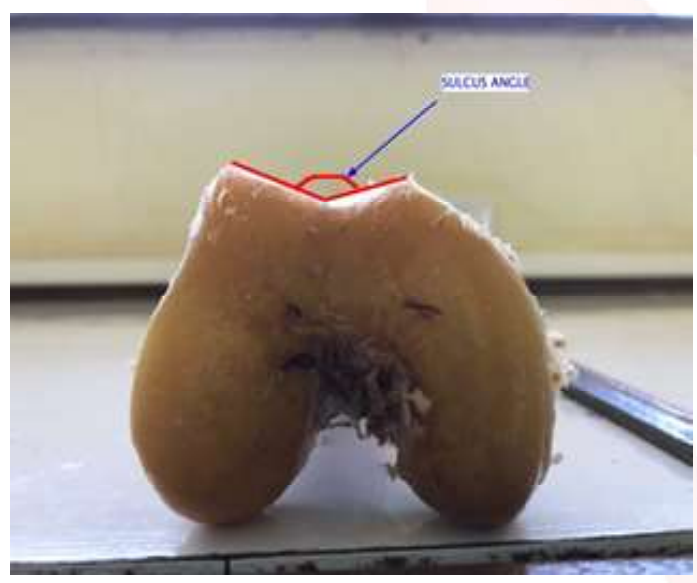

Fig. 1: Measurement of sulcus angle.

The specimens were placed on a flat board and an end-on digital photograph of the distal femur taken. This was adopted from the method by Murshed et al [10]. The pictures were uploaded to a computer and the angles measured using Image ${ }^{\circledR}$ (National Institutes of Health, Bethesda, Maryland), an open-source image analysis software. The angle formed by the intersection of lines drawn from the most prominent points of both the lateral and medial femoral condyles was taken as the sulcus angle and measured (Figure 1). For the lateral trochlea inclination angle, a line was drawn tangential to the posterior aspect of the condyles and the angle formed between that and a line along the anterior aspect of the lateral trochlea facet was measured (Figure 2). The data obtained was entered and analyzed on an Excel $^{\circledR}$ spreadsheet (Microsoft Corporation). Measures of central tendency were obtained. For comparisons, a $p$ value of less than 0.05 was taken as significant.

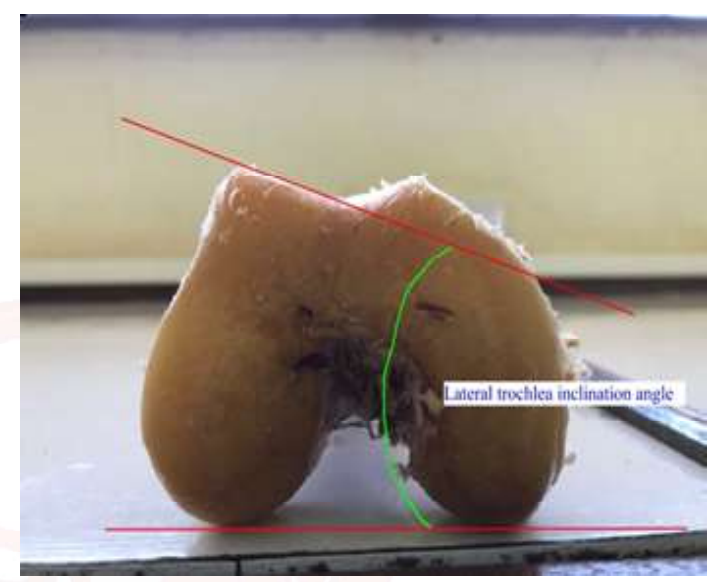

Fig. 2: Measurement of lateral trochlea inclination angle.

\section{RESULTS}

A total of 23 unpaired femora, of undetermined sex were obtained. Twelve (12) were right-sided while 11 were left-sided. An average sulcus angle of $139^{\circ}$ was obtained for all specimens, with the average angle for right femora being $137^{\circ}$ and $141^{\circ}$ for the left femora. There was no significant difference between the angles for the right and left femora ( $p$ value 0.58 ). The average lateral trochlea inclination angle was 210 , the minimum being $11^{\circ}$ and maximum being $27^{\circ}$.There was no significant difference between the trochlea inclination angles for the right and left femora ( $p$ value 0.58). These values are summarized in Table 1.

Table 1: Sulcus and lateral trochlea inclination angles of Kenyan femora.

\begin{tabular}{|lccc|}
\hline & All specimens & Right femora & Left femora \\
& $(\mathrm{n}=23)$ & $(\mathrm{n}=12)$ & $(\mathrm{n}=11)$ \\
\hline Mean sulcus angle & $139^{\circ}$ & $137^{\circ}$ & $141^{\circ}$ \\
\hline Minimum sulcus angle & $120^{\circ}$ & $120^{\circ}$ & $123^{\circ}$ \\
\hline Maximum sulcus angle & $161^{\circ}$ & $160^{\circ}$ & $161^{\circ}$ \\
\hline Mean lateral inclination angle & $21^{\circ}$ & $20^{\circ}$ & $21^{\circ}$ \\
\hline Minimum lateral inclination angle & $11^{\circ}$ & $13^{\circ}$ & $11^{\circ}$ \\
\hline Maximum lateral inclination angle & $27^{\circ}$ & $25^{\circ}$ & $27^{\circ}$ \\
\hline
\end{tabular}


Table 2: Comparison between results of current study and other populations.

\begin{tabular}{|c|c|c|c|c|c|}
\hline Author & Study type & Ethnicity & $\begin{array}{c}\text { Mean sulcus angle } \\
\text { (0) }\end{array}$ & $\begin{array}{c}\text { Mean sulcus angle } \\
\text { right femora }\end{array}$ & $\begin{array}{c}\text { Mean sulcus angle } \\
\text { left femora }\end{array}$ \\
\hline Current study & Dry bone study & Kenyan & 139 & 137 & 141 \\
\hline Murshed et al [10] & Dry bone study & Turkish & 141.2-Both gender & 142.2 & 141.2 \\
\hline \multirow[t]{2}{*}{ Mwakikunga et al [11] } & Dry bone study & Malawians & 142.4 & 142.9-males & 141.8-males \\
\hline & & & & 144.3-females & 140.6-females \\
\hline Qin et al [12] & $\begin{array}{c}\text { 3D CT images } \\
\text { normal subjects }\end{array}$ & Chinese & 154.41 & & \\
\hline
\end{tabular}

A plot of the trochlea sulcus angle and the lateral trochlea inclination angle showed a negative correlation, as shown in Figure 3.

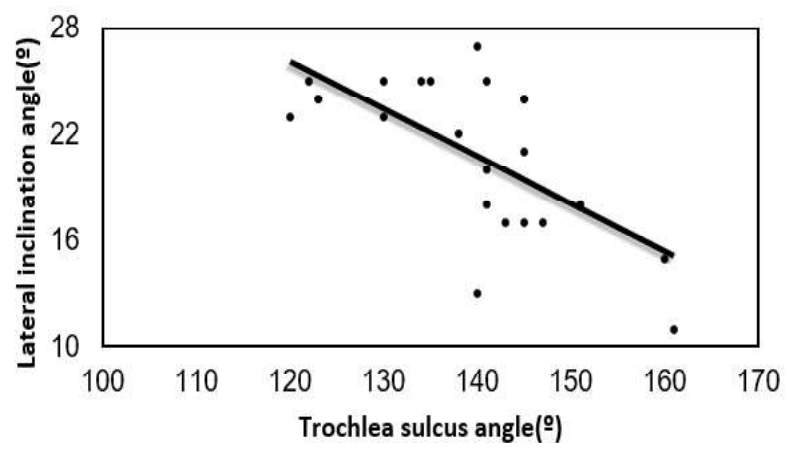

Fig. 3: Relationship between trochlea sulcus and lateral trochlea inclination angles.

\section{DISCUSSION}

The current study has shown the average trochlear sulcus in adult Kenyan femora to be $139^{\circ}$, with no significant difference between the right and left sides. These figures are close to those obtained by Murshed et al in a dry bone study in a Turkish population, who found an average sulcus angle of $141.2^{\circ}$ [10]. Mwakikunga et al, in an osteological study in a Malawian population found a mean angle of $142.4^{\circ}$ [11], which is close to the figures obtained in the current study. A study on normal Chinese subjects using 3D CT images reported a mean angle of $154.41^{\circ}[12]$. This difference in the angles could be due to population differences or differences in the methods of measurement, as the current study utilized analysis of images using image processing software. The angle at which the measurements are taken can also influence the values obtained, with progressive reduction as the angle of knee flexion increases $[13,14]$.

Studies have shown that the osseous sulcus angle is inversely related to age, being flatter in the youngest children and progressively reducing with age [15]. In the fetus, the cartila- -ginous sulcus angle, however, approaches the adult osseous sulcus angle, showing that the bony angle develops progressively as ossification of the distal femur proceeds [16]. Wide sulcus angles are associated with trochlear dysplasia and patella instability [2]. In a comparative study of patients with patella instability and controls in an Egyptian population, Ebrahim et al found patients with patella instability had a mean angle of $152.7^{\circ}$ whilst the control group had a mean angle of $134.4^{\circ}$ [17]. Similar findings were reported by van Huyssteen et al who found a mean bony sulcus angle of $167.9^{\circ}$ in patients with patella instability and dysplastic knees and $138.2^{\circ}$ in controls [18]. The same authors found that the cartilaginous sulcus angle was generally shallower compared to the bony sulcus angle, in both dysplastic and normal knees [18]. The implication of their finding, especially in resource-poor settings, is that because many patients are investigated using plain radiography using either the Merchant [19] or Brattstrom [2] views, the bony sulcus angle visualized is narrower than the cartilaginous angle, thus underestimating the angle. A wide angle has also been shown to be associated with patellofemoral pain and lateral patella tilt, which is associated with patella instability [20].

The lateral trochlea inclination angle has been used as a measure of trochlea dysplasia, with an angle less than $11^{\circ}$ associated with trochlea dysplasia and patella instability [5]. In the present study, the mean lateral inclination angle was $21^{\circ}$ with a minimum of $11^{\circ}$. The trochlea sulcus and lateral inclination angle were found to be negatively correlated, with the inclination angle reducing as the sulcus angle increased. This is not unexpected because as the sulcus angle increases towards a shallow dysplastic angle, the inclination angle would also reduce. 
Patellofemoral complications after patellofemoral and total knee replacement can be as a result of surgical technique like errors in implant size, positioning and soft tissue balancing. The geometry of the trochlea in the femoral component i.e. curvature, depth and angle has also been implicated in causation of patello-femoral symptoms after total knee replacement [21]. Earlier designs had wider angles which have subsequently been reduced in newer designs to try and replicate the anatomy of the native femoral trochlea [9]. There is a dearth of local studies on outcomes especially patellofemoral symptoms, which, elsewhere, are responsible for patient dissatisfaction and revisions.

A limitation of the current study is that it was done on dried femora of unknown gender, without a previous medical history like patella instability. It can however form the basis for further local clinical studies on the relationship between the sulcus angle and patella instability and patellofemoral outcomes after total knee replacement. The results can also be useful in designs of both patellofemoral and total knee implants for use in the local population.

\section{CONCLUSION}

The current study has found that the average sulcus angle in Kenyan femora is $139^{\circ}$ and the average lateral trochlea inclination angle 210, with no significant difference between right and left sides. This can be used as a guide when analyzing diagnostic images of the knee. Further local clinical studies should be done on the relationship between the sulcus angle, lateral trochlea inclination angle and patella instability.

\section{Conflicts of Interests: None}

\section{REFERENCES}

[1]. Harbaugh CM, Wilson NA, Sheehan FT. Correlating femoral shape with patellar kinematics in patients with patellofemoral pain. J Orthop Res. 2010;28(7):865-872.

https://doi.org/10.1002/jor.21101

PMid:20108348 PMCid:PMC3269909

[2]. Brattström H. Shape of the Intercondylar Groove Normally and in Recurrent Dislocation of Patella: A Clinical and X-Ray Anatomical Investigation. Acta Orthop Scand. 1964 May;35(sup68):1-148.

https://doi.org/10.3109/ort.1964.35.suppl-68.01
[3]. Davies-Tuck M, Teichtahl AJ, Wluka AE, Wang Y, Urquhart DM, Cui J, et al. Femoral sulcus angle and increased patella facet cartilage volume in an osteoarthritic population. Osteoarthritis Cartilage. 2008;16(1):131-135. https://doi.org/10.1016/ j.joca.2007.08.002 PMid:17869546

[4]. Macri EM, Culvenor AG, Morris HG, Whitehead TS, Russell TG, Khan KM, et al. Lateral displacement, sulcus angle and trochlear angle are associated with early patellofemoral osteoarthritis following anterior cruciate ligament reconstruction. Knee Surg Sports Traumatol Arthrosc. 2018;26(9):2622-2629. https://doi.org/10.1007/s00167-017-4571-1 PMid:28488001

[5]. Carrillon Y, Abidi H, Dejour D, Fantino O, Moyen B, Tran-Minh VA. Patellar instability: assessment on MR images by measuring the lateral trochlear inclination-initial experience. Radiology. 2000 Aug;216(2):582-5. https://doi.org/10.1148/ radiology.216.2.r00au07582 PMid:10924589

[6]. Russell RD, Huo MH, Jones RE. Avoiding patellar complications in total knee replacement. Bone Joint J. 2014;96-B:84-86 https://doi.org/10.1302/0301620X.96B11.34305 PMid:25381415

[7]. Malo M, Vince KG. The Unstable Patella After Total Knee Arthroplasty: Etiology, Prevention, and Management. JAAOS - J Am Acad Orthop Surg. 2003 Oct;11(5):364-371. https://doi.org/10.5435/ 00124635-200309000-00009 PMid:14565758

[8]. Kamath AF, Slattery TR, Levack AE, Wu CH, Kneeland $\mathrm{JB}$, Lonner JH. Trochlear inclination angles in normal and dysplastic knees. J Arthroplasty. 2013 Feb;28(2):214-9. https://doi.org/10.1016/ j.arth.2012.04.017 PMid:22704031

[9]. Saffarini M, Ntagiopoulos PG, Demey G, Le Negaret B, Dejour DH. Evidence of trochlear dysplasia in patellofemoral arthroplasty designs. Knee Surg Sports Traumatol Arthrosc. 2014;22(10):2574-2581. https://doi.org/10.1007/s00167-014-2967-8 PMid:24696005

[10]. Murshed - Femoral Sulcus Angle Measurements An Anatomical S.pdf [Internet]. [cited 2020 Mar 16]. Available from: http://journals.tubitak.gov.tr/medical/issues/sag-04-34-3/sag-34-3-3-0306-13.pdf

[11]. Mwakikunga A, Katundu K, Msamati B, Adefolaju AG, Schepartz L. An anatomical and osteometric study of the femoral sulcus angle in adult Malawians. Afr Health Sci. 2016;16(4):1182-7. https://doi.org/10.4314/ahs.v16i4.38 PMid:28479913 PMCid:PMC5398467

[12]. Qin J, Chen D, Xu Z, Shi D, Dai J, Jiang Q. Evaluation of the Effect of the Sulcus Angle and Lateral to Medial Facet Ratio of the Patellar Groove on Patella Tracking in Aging Subjects with Stable Knee Joint. BioMed Res Int. 2018; 2018:1-5. https://doi.org/ 10.1155/2018/4396139 PMid:29854753 PMCid: PMC5964416

[13]. Davies AP, Bayer J, Owen-Johnson S, Shepstone L, Darrah C, Glasgow MM, et al. The optimum knee flexion angle for skyline radiography is thirty 
degrees. Clin Orthop Relat Res 2004;423: 166-171. https://doi.org/10.1097/01.blo.0000129160.07965.e7 PMid: 15232444

[14]. Saffarini M, Demey G, Nover L, Dejour D. Evolution of trochlear compartment geometry in total knee arthroplasty. Ann Transl Med. 2016;4(1).

[15]. Nietosvaara Y. The femoral sulcus in children. An ultrasonographic study. J Bone Joint Surg Br. 1994 Sep;76-B(5):807-9. https://doi.org/10.1302/0301620X.76B5.8083274

[16]. Glard Y, Jouve JL, Panuel $M$ et al. An anatomical and biometrical study of the femoral trochlear groove in the human fetus. J Anat. 2005;206:411-413.

https://doi.org/10.1111/j.1469-7580.2005.00400.x PMid:15817109 PMCid:PMC1571485

[17]. Osman NM, Ebrahim SM. Patellofemoral instability: Quantitative evaluation of predisposing factors by MRI. Egypt J Radiol Nucl Med. 2016;47(4):15291538. https://doi.org/10.1016/j.ejrnm.2016.09.020

[18]. Van Huyssteen AL, Hendrix MRG, Barnett AJ, Wakeley CJ, Eldridge JDJ. Cartilage-bone mismatch in the dysplastic trochlea: AN MRI STUDY. J Bone Joint Surg Br. 2006 May;88-B(5):688-91. https://doi.org/10.1302/ 0301-620X.88B5.16866 PMid:16645122
[19]. Merchant AC, Mercer RL, Jacobsen RH, Cool CR. Roentgenographic Analysis of Patellofemoral Congruence. JBJS. 1974 Oct;56(7):1391-1396. https:// doi.org/10.2106/00004623-197456070-00007

[20]. Stefanik JJ, Roemer FW, Zumwalt AC, Zhu Y, Gross KD, Lynch JA, Frey-Law LA, Lewis CE, Guermazi A, Powers $\mathrm{CM}$, Felson DT. Association between measures of trochlear morphology and structural features of patellofemoral joint osteoarthritis on MRI: the MOST study. J Orthop Res 2012;30:1-8. https:// doi.org/10.1002/jor.21486 PMid:21710542 PMCid:PMC3217080

[21]. Varadarajan KM, Rubash HE, Li G. Are current total knee arthroplasty implants designed to restore normal trochlear groove anatomy? J Arthroplasty. 2011;26(2):274-281. https://doi.org/10.1016/ j.arth.2009.12.009 PMid:20171042

\author{
How to cite this article: \\ Lakati Kevin Christopher, Arisi Kerubo, Yegon Fred, Mwaniki Mark, \\ Mutero Flora. TROCHLEA SULCUS AND LATERAL TROCHLEA INCLINA- \\ TION ANGLES IN KENYANS: AN OSTEOMETRIC STUDY. Int I Anat Res \\ 2020;8(3.2):7649-7653. DOI: 10.16965/ijar.2020.176
}

